\title{
Thermal performance of a gas turbine based on an exergy analysis
}

\author{
Abdallah Haouam ${ }^{1, *}$, Chaima Derbal', and Hocine Mzad $^{1}$ \\ ${ }^{1}$ Mechanical Engineering Department, Faculty of Engineering, Badji Mokhtar University - PO Box. 12 Annaba 23000 Algeria \\ ${ }^{2}$ Industrial mechanics laboratory, Mechanical Engineering Department, Faculty of Engineering, Badji Mokhtar University - \\ PO Box. 12 Annaba 23000 Algeria
}

\begin{abstract}
This work concerns the calculation and the analysis of the thermal performance of the components of an MS 7001 type gas turbine with a nominal power of $87 \mathrm{MW}$ using the concept of exergy. The exergy balance is used in addition to the energy balance to estimate the irreversibility of the air compressor, the combustion chamber and the turbine. The exergy analysis is carried out by applying the equilibrium equations obtained from the general definitions of the irreversibility of the thermodynamic processes and the data provided by the manufacturer. The results show that the exergy destruction of the gas turbine depends on the variation of the thermodynamic parameters: ambient temperature, compression ratio, air-fuel ratio. The combustion chamber has the highest exergy destruction estimated at $36.34 \mathrm{MW}$. The air compressor has an exergy efficiency of $84.19 \%$ that of the combustion chamber is $75.91 \%$ while that of the turbine expansion is $92.58 \%$. The total exergy destruction of the gas turbine is $53.51 \mathrm{MW}$ and its efficiency is $32.44 \%$. Improving the performance of the gas turbine requires decreasing the temperature of the intake air.
\end{abstract}

\section{Introduction}

The present work relates to the determination of performance of a gas turbine-type GE Frame 7, rated power $87 \mathrm{MW}$, using a fuel oil of LHV 46.64 MJ / kg, the centerpiece of the mixed refrigeration loop (MR) in the Natural Gas Liquefaction process at Skikda, Algeria. The loop includes two 2 stages compressors providing a low temperature refrigeration to liquefy the natural gas in a main heat exchanger (Fig. 1). These two axial and centrifugal compressors, with a nominal capacity of $1.347419 \mathrm{~kg} / \mathrm{h}$, are driven by the gas turbine subject of this study and a start-up engine of $17 \mathrm{MW}$, mounted on the same shaft. The Mixed refrigerant (MR) used in the compressors to liquefy natural gas is a mixture of molar composition: $48.90 \%$ methane, $37.15 \%$ ethane, $8.73 \%$ propane and $5.22 \%$ nitrogen.

Since the specific atmospheric conditions in Skikda differ from ISO requirements $\left(1 \mathrm{~atm}, \quad 15^{\circ} \mathrm{C}\right.$ and $60 \%$ humidity); the gas turbine performance could be affected. Its power will decrease due to high temperatures causing a decrease in the mass flow of air decreases. Efficiency also decreases because compressors require more power at a higher temperature.

The energy balance is not useful for analyzing the performance of equipment in the refrigeration loop because the real inefficiencies of the process are not related to heat loss but to exergetic destruction. Hence the use of an exergetic analysis to detect irreversibilities within the equipment of the MR loop. The evaluation of the exergy destruction of each component in the process, will allow the assessment of the overall effectiveness of this natural gas liquefaction process. In this paper, we will limit our investigation to the examination of the gas turbine as a first objective.

Many researchers have investigated the effects of operating conditions on the performance of power plants. Al Doori [1] reportedly carried out an exergy analysis for a thermal power station in India with a $159 \mathrm{MW}$ gas turbine using fuel oil ( $\mathrm{LHV}=42.9 \mathrm{MJ} / \mathrm{kg}$ ). The rate of exergetic destruction in the turbine was about $5.4 \%$, while that in the combustion chamber was about $36.4 \%$.

Abam et al [2] performed an exergy analysis of a 33 MW gas turbine power plant in Nigeria using natural gas. The simulation results showed that the exergetic efficiency of the entire system when the temperature of air at the compressor inlet was $302 \mathrm{~K}$ and that of the turbine to $1087 \mathrm{~K}$ was $25.8 \%$. In addition, the combustion chamber had the highest exergetic destruction (65 MW) and the gas turbine, the lowest exergetic destruction $(0.45 \mathrm{MW})$.

Kakaras [3] reported that the efficiency of the gas turbine is strongly related to the ambient air temperature. According to the gas turbine type, the output power is reduced by 5 to $10 \%$ of the rated power at $288 \mathrm{~K}$ according to the ISO standard for each increase of $10 \mathrm{~K}$ in the temperature of the ambient air. At the same time, the specific consumption of fuel increases from 1.5 to $4 \%$.

\footnotetext{
* Corresponding author: abdallah.haouam@univ-annaba.dz
} 


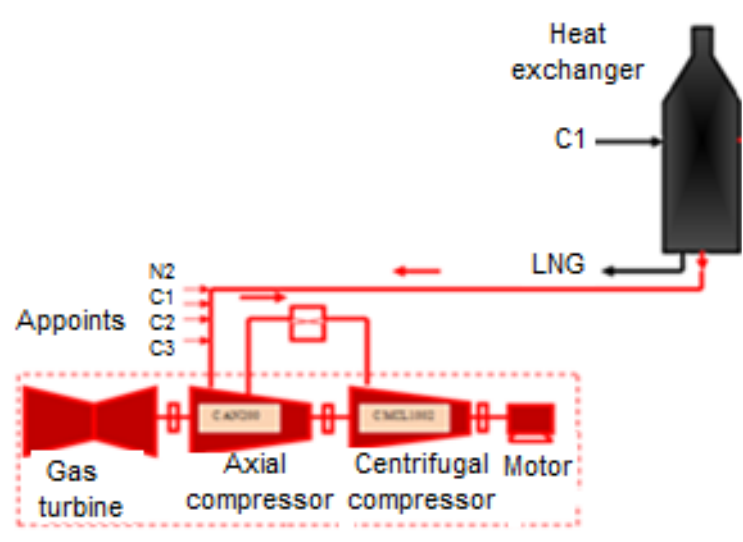

Fig. 1. Mixed refrigeration process (MR) scheme of LNG Skikda, Algeria

\section{Theoretical background}

Exergy is the maximum amount of useful work that can be extracted in theory from a system when it is brought to equilibrium with its environment. It is expressed by equation (1) where $h_{0}$ and $\mathrm{s}_{0}$ are enthalpy and entropy at room temperature $T_{0}$ and at atmospheric pressure $P_{0}$. Unlike energy, exergy depends not only on the state of the system, but also on the state of the external environment [4-6].

$$
\begin{gathered}
e x=\left(h-h_{0}\right)-T_{0}\left(s-s_{0}\right) \\
h-h_{0}=C_{p}\left(T-T_{0}\right) ; \text { Ideal gas } \\
d S=d h-v d P \\
s-s_{0}=C_{p} \ln \frac{T}{T_{0}}-R \ln \frac{P}{P_{0}}
\end{gathered}
$$

Combining equations (2), (3) and (4) we get:

$$
e x=C_{p}\left(T-T_{0}\right)-T_{0}\left(C_{p} \ln \frac{T}{T_{0}}-R \ln \frac{P}{P_{0}}\right)
$$

Exergy per unit time is:

$$
\dot{E x}=\dot{m} e x
$$

The exergy balance for each component of the gas turbine (Fig. 2) will make a quantitative assessment of energy degradation, i.e. the estimation of exergy losses of each element.
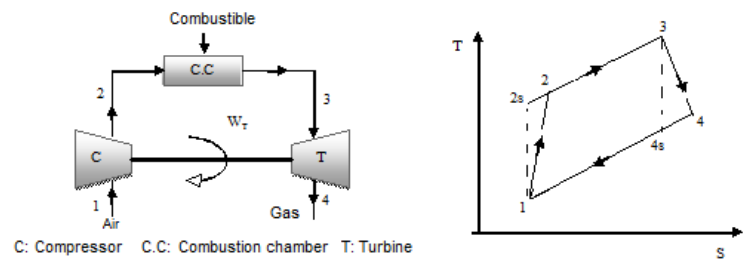

Fig. 2. Schematic diagram of the gas turbine and the associated Brayton cycle
The exergy analysis was performed by applying the

\begin{tabular}{|c|c|c|}
\hline Parameters & Unit & Value \\
\hline Ambient air temperature & ${ }^{\circ} \mathrm{C}$ & 25 \\
\hline Air inlet pressure & Bar & 1.013 \\
\hline Outlet compressor pressure & Bar & 10.38 \\
\hline Inlet compressor temperature & ${ }^{\circ} \mathrm{C}$ & 26.43 \\
\hline $\begin{array}{l}\text { Outlet combustion chamber } \\
\text { temperature }\end{array}$ & ${ }^{\circ} \mathrm{C}$ & 1200 \\
\hline Mass flow rate of the air & $\mathrm{kg} / \mathrm{s}$ & 121 \\
\hline Mass flow rate of the fuel & $\mathrm{Kg} / \mathrm{s}$ & 2.69 \\
\hline Heat capacity of the air & $\mathrm{J} / \mathrm{kg} \cdot \mathrm{K}$ & 1005 \\
\hline Heat capacity of the gas & $\mathrm{J} / \mathrm{kg} \cdot \mathrm{K}$ & 1110 \\
\hline Specific constant of MR gas & $\mathrm{J} / \mathrm{kg} \cdot \mathrm{K}$ & 341.72 \\
\hline Specific constant of the air & $\mathrm{J} / \mathrm{kg} \cdot \mathrm{K}$ & 287 \\
\hline Adiabatic exponent & & 1.4 \\
\hline Turbine isentropic efficiency & & 0.87 \\
\hline isentropic & & 0.87 \\
\hline $\begin{array}{l}\text { Compressor mechanical } \\
\text { efficiency }\end{array}$ & & 0.90 \\
\hline $\begin{array}{ll}\text { Combustion } & \text { chamber } \\
\text { efficiency } & \end{array}$ & & 0.97 \\
\hline
\end{tabular}
above derived equations with the data provided in Table 1 and based on the schematic diagram of the components of the gas turbine (Fig. 3).

Table 1. Operating conditions used for the exergy analysis [7]
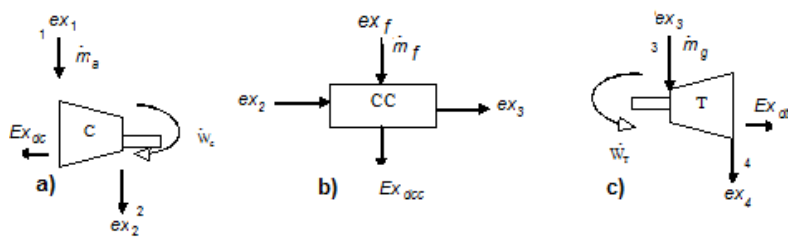

Fig. 3. Schematic diagram of the components of the gas turbine: a) C: compressor; b) CC: combustion chamber and c): $\mathrm{T}$ : turbine expansion

\section{Compression section (C)}

Exergy equation for the compressor:

$$
\begin{gathered}
\dot{m}_{a} e x_{1}+\dot{W}_{C}=\dot{m}_{a} e x_{2}+\dot{E x_{d c}} \\
E x_{d c}=\dot{W}_{C}-\dot{m}_{a}\left(e x_{2}-e x_{1}\right) \\
E \dot{x}_{d c}=\dot{W}_{C}-\dot{m}_{a}\left[C_{p a}\left(T_{2}-T_{1}\right)-T_{0}\left(C_{p a} \ln \frac{T_{2}}{T_{1}}-\right.\right. \\
\left.\left.R_{a} \ln \frac{P_{2}}{P_{1}}\right)\right] \quad \\
\dot{W}_{C}=\frac{\dot{m}_{a} C_{p a}\left(T_{2}-T_{1}\right)}{\eta_{m}}
\end{gathered}
$$

From the equation governing the isentropic transformation and from the definition of the isentropic 
efficiency, temperatures in the compressor output will be determined:

$$
\begin{aligned}
& \frac{T_{2 s}}{T_{1}}=\left(\frac{P_{2}}{P_{1}}\right)^{\frac{\gamma-1}{\gamma}}=\tau^{\frac{\gamma-1}{\gamma}} \Rightarrow T_{2 s}=T_{1} \times \tau^{\frac{\gamma-1}{\gamma}} \\
& \eta_{s c}=\frac{T_{2 S}-T_{1}}{T_{2}-T_{1}} \Rightarrow T_{2}=T_{1}+\frac{T_{2 s}-T_{1}}{\eta_{s c}}
\end{aligned}
$$

Exergy efficiency of the compressor is given by the following equation:

$$
\varepsilon_{e x c}=\frac{\dot{W}_{C}-E x_{d c}}{\dot{W}_{C}}=\frac{\dot{m}_{a}\left(e x_{2}-e x_{1}\right)}{\dot{W}_{c}}
$$

\section{Combustion section (CC)}

Exergy equation for the combustion chamber:

$$
\begin{aligned}
& \dot{m}_{a} e x_{2}+\dot{m}_{f} e x_{f}=\dot{m}_{g} e x_{3}+\dot{E} x_{d c c} \\
& \dot{E} x_{d c c}=\dot{m}_{a} e x_{2}+\dot{m}_{f} e x_{f}-\dot{m}_{g} e x_{3}
\end{aligned}
$$

The exergy of the fuel is determined by:

$$
e x_{f}=\gamma_{f} . P C I
$$

$\gamma_{f}=1.02$ is the exergy factor based on the lower calorific value of the fuel used.

$$
\begin{gathered}
\dot{E x_{d c c}}=\dot{m}_{a}\left[C_{p a}\left(T_{2}-T_{0}\right)-T_{0}\left(C_{p a} \ln \frac{T_{2}}{T_{0}}-\right.\right. \\
\left.\left.R_{a} \ln \frac{P_{2}}{P_{0}}\right)\right]+\dot{m}_{f}\left(\gamma_{f} \cdot P C I\right)-\dot{m}_{g}\left[C_{p g}\left(T_{3}-T_{0}\right)-\right. \\
\left.T_{0}\left(C_{p g} \ln \frac{T_{3}}{T_{0}}-R_{g} \ln \frac{P_{3}}{P_{0}}\right)\right]
\end{gathered}
$$

The mass flow rate of natural gas in the combustion chamber is determined by the ratio:

$$
f=\frac{Q_{c c}}{P C I}=\frac{\dot{m}_{f}}{\dot{m}_{a}}
$$

$Q_{c c}$ is the heat of combustion determined by:

$$
Q_{c c}=\frac{C_{p g T_{3}}-C_{p a} T_{2}}{\eta_{c c}}
$$

Exergy efficiency of the combustion chamber :

$$
\varepsilon_{e x c c}=\frac{\dot{m}_{g} e x_{3}}{\dot{m}_{a} e x_{2}+\dot{m}_{f} e x_{f}}=1-\frac{E x_{d c c}}{\dot{m}_{a} e x_{2}+\dot{m}_{f}\left(\gamma_{f} \cdot P C I\right)}
$$

\section{Expansion section (T):}

The balance equation Exergy expansion section of the turbine is given by:

$$
\begin{gathered}
\dot{m}_{g} e x_{3}=\dot{W}_{T}+\dot{E} x_{d T}+\dot{m}_{g} e x_{4} \\
\dot{E} x_{d T}=\dot{m}_{g}\left(e x_{3}-e x_{4}\right)-\dot{W}_{T} \\
\dot{E} x_{d T}=\dot{m}_{g}\left[C_{p g}\left(T_{3}-T_{4}\right)-T_{0}\left(C_{p g} \ln \frac{T_{3}}{T_{4}}-R_{g} \ln \frac{P_{3}}{P_{4}}\right)\right] \\
-\dot{W}_{T}
\end{gathered}
$$

$$
\begin{gathered}
\eta_{s T}=\frac{W_{T}}{W_{S T}} \Rightarrow W_{T}=\eta_{s T} . \\
W_{s T}=\dot{m}_{g} C p_{g}\left(T_{3}-T_{4 s}\right) \\
\frac{T_{3}}{P_{3} \frac{\gamma-1}{\gamma}}=\frac{T_{4 s}}{P_{4 s} \frac{\gamma-1}{\gamma}} \Rightarrow T_{4 s}=T_{3} \cdot\left(\frac{P_{4 s}}{P_{3}}\right)^{\frac{\gamma-1}{\gamma}} \\
T_{4 s}=T_{3}\left(\frac{P_{4}}{P_{3}}\right)^{\frac{\gamma-1}{\gamma}}=T_{3} \cdot\left(\frac{P_{1}}{P_{2}}\right)^{\frac{\gamma-1}{\gamma}}=T_{3} \cdot\left(\frac{1}{\tau}\right)^{\frac{\gamma-1}{\gamma}}
\end{gathered}
$$

Turbine outlet temperature $T_{4}$ :

$$
\eta_{s T}=\frac{T_{3}-T_{4}}{T_{3}-T_{4 s}} \Rightarrow T_{4}=T_{3}-\eta_{s T}\left(T_{3}-T_{4 s}\right)
$$

Exergy efficiency of the expansion through the turbine:

$$
\begin{gathered}
\varepsilon_{e x T}=\frac{\dot{W}_{T}}{\dot{m}_{g}\left(e x_{3}-e x_{4}\right)} \\
\varepsilon_{e x T}=1-\frac{\dot{E} x_{d T}}{\dot{m}_{g}\left(e x_{3}-e x_{4}\right)}
\end{gathered}
$$

\section{Results and discussion}

Exergy analysis results of the gas turbine according to the given operating conditions are shown in Table 2 and Figures 4, 5 and 6.

Table 2. Exergy analysis results of the gas turbine according to the operating conditions (Tab. 1).

\begin{tabular}{|l|c|c|c|}
\hline \multicolumn{1}{|c|}{ Component } & $\begin{array}{c}\dot{E} x_{d} \\
(\mathrm{MW})\end{array}$ & $\begin{array}{c}(\%) \\
\dot{E x}\end{array}$ & $\begin{array}{r}\varepsilon_{\mathrm{ex}} \\
(\%)\end{array}$ \\
\hline Compressor (C) & 6.94 & 12.96 & 84.19 \\
\hline Combustion chamber (CC) & 39.73 & 74.24 & 75.91 \\
\hline Turbine expansion (T) & 6.84 & 12.80 & 92.58 \\
\hline Gas turbine & 53.51 & 100 & 32.44 \\
\hline
\end{tabular}

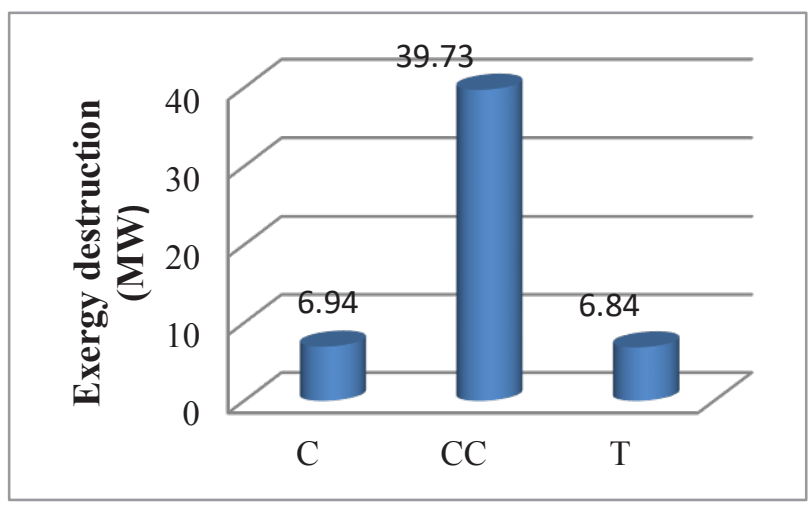

Fig. 4. Distribution of Exergy destruction at each component of the gas turbine 


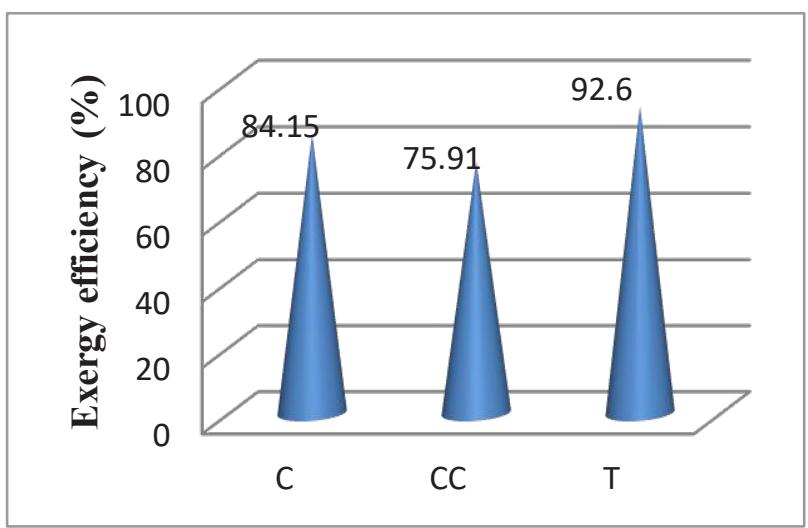

Fig. 5. Exergy efficiency of each component of the gas turbine

The maximum exergy destruction is in the combustion chamber and is $39.73 \mathrm{MW}$. For this reason, its exergy efficiency is the lowest compared to other components of the gas turbine. The values of the exergy efficiency are respectively: $84.19 \%$ for the compressor, $75.91 \%$ for the combustion chamber and $92.58 \%$ for the expansion through the turbine.

Global Exergy destruction of the gas turbine will be the sum of the destruction in the 03 components:

$$
E x_{d}=53.51 M W
$$

The Exergy efficiency of the gas turbine in the operating conditions will be determined by:

$$
\varepsilon_{\text {Tgaz }}=\frac{\dot{W}_{U}}{\dot{Q}_{c c}}=\frac{\dot{W}_{T}-\dot{W}_{C}}{\dot{Q}_{c c}}=\frac{85.44-43.91}{128}=32.44 \%
$$

The exergy destruction of the gas turbine depends on the variation of thermodynamic variables: pressure and temperature, for deduction of the compression ratio and the air-fuel ratio. The operating conditions of the gas turbine are decisive in the analysis of its thermodynamic performance. For this, the exergy analysis was performed according to the variation of the ambient air intake temperature to the compressor between -2 and 45 - C. The performance results of the gas turbine as a function of the variation of the ambient air temperature are summarized in Table 3 and Figures 6 and 7.
Table 3. Evolution of exergy performance of the gas turbine as a function of the change in ambient air temperature $T_{1}$

\begin{tabular}{|c|c|c|c|c|c|c|}
\hline $\boldsymbol{T}_{\mathbf{1}}$ & $\begin{array}{c}\dot{W}_{\boldsymbol{C}} \\
(\mathrm{MW})\end{array}$ & $\begin{array}{c}\boldsymbol{E} \boldsymbol{x}_{\boldsymbol{d} c} \\
(\mathrm{MW})\end{array}$ & $\begin{array}{c}\boldsymbol{\varepsilon}_{\text {exc }} \\
(\%)\end{array}$ & $\begin{array}{c}\boldsymbol{E} \boldsymbol{x}_{\text {dcc }} \\
(\mathrm{MW})\end{array}$ & $\begin{array}{c}\boldsymbol{\varepsilon}_{\text {ex cc }} \\
(\%)\end{array}$ & $\begin{array}{c}\boldsymbol{\varepsilon}_{\text {ex Tgaz }} \\
(\%)\end{array}$ \\
\hline 271.2 & 39.78 & 6.53 & 83.58 & 32.75 & 79.27 & 35.67 \\
\hline 276.4 & 40.52 & 6.60 & 83.71 & 34.08 & 78.60 & 35.09 \\
\hline 281.6 & 41.28 & 6.63 & 83.93 & 35.37 & 77.97 & 34.50 \\
\hline 286.8 & 42.05 & 6.75 & 83.95 & 36.63 & 77.37 & 33.89 \\
\hline 292 & 42.80 & 6.82 & 84.06 & 37.97 & 76.73 & 33.31 \\
\hline 297.3 & 43.59 & 6.91 & 84.15 & 39.31 & 76.11 & 32.69 \\
\hline 299.4 & 43.91 & 6.94 & 84.19 & 39.73 & 75.91 & 32.44 \\
\hline 302.5 & 44.34 & 6.97 & 84.28 & 40.66 & 75.49 & 32.11 \\
\hline 307.7 & 45.11 & 7.05 & 84.37 & 41.96 & 74.90 & 31.50 \\
\hline 312.9 & 45.87 & 7.13 & 84.45 & 43.30 & 74.30 & 30.91 \\
\hline 318.2 & 46.65 & 7.21 & 84.54 & 44.62 & 73.73 & 30.30 \\
\hline
\end{tabular}

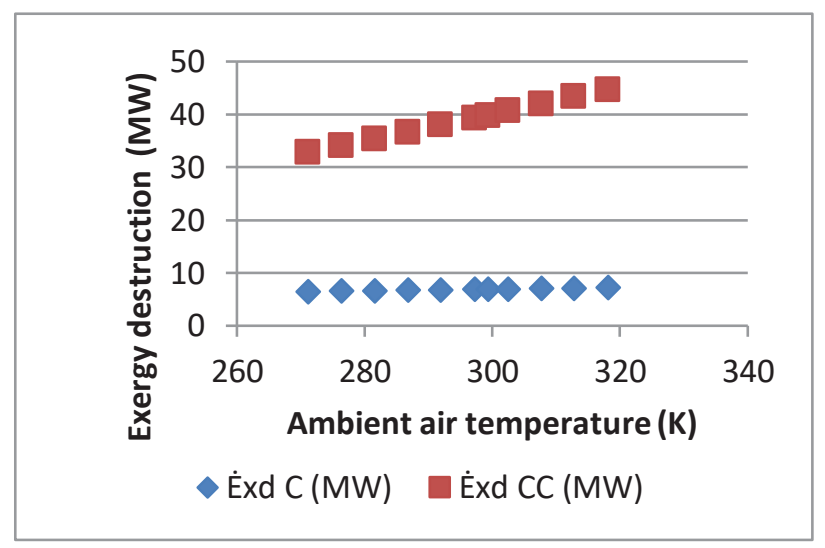

Fig. 6. Evolution of exergy destruction of the gas turbine as a function of the change in ambient air temperature $T_{1}$

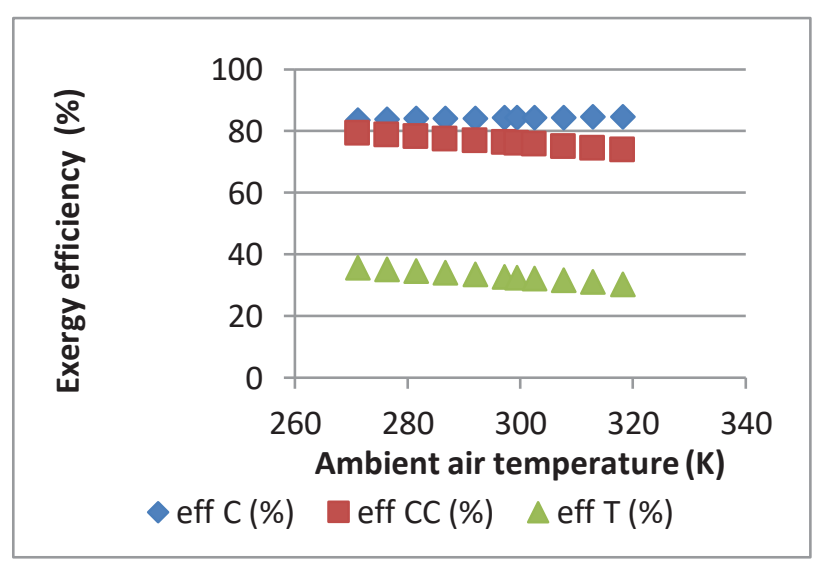

Fig. 7. Evolution of exergy efficiency of the gas turbine as a function of the change in ambient air temperature $T_{1}$ 
During the increase of the ambient air temperature from $271 \mathrm{~K}$ to $318 \mathrm{~K}\left(-2\right.$ to $\left.45^{\circ} \mathrm{C}\right)$, the exergetic destruction increases slightly in the compressor from 6.53 to $7.21 \mathrm{MW}$, it increases more significantly within the chamber combustion from 32.75 to $44.62 \mathrm{MW}$ (Fig. 6 ); while the exergy efficiency goes from $83.58 \%$ to $84.54 \%$ for the compressor, decreases from 79.27 to $73.73 \%$ for the combustion chamber; that of the gas turbine as a whole decreases from 35.67 to $30.30 \%$ (Fig. 7).

An increase in air temperature causes a small increase in the exergy destruction of the compressor. Increasing the temperature of ambient air will also increase the exergy destruction in the combustion chamber and decrease the exergy destruction in the turbine.

\section{Conclusion}

The Exergy balance of a thermodynamic system allows the determination of the Exergy destruction or the estimate of the energy losses due to the irreversibility of actual transformations. This leads to the quantitative measurement of the Exergy efficiency. The results show that the efficiency of the combustion chamber is the lowest compared to that of the compressor and the expansion in the turbine because it is where the highest exergy destruction takes place. The total exergy destruction of the $84.55 \mathrm{MW}$ gas turbine is $53.51 \mathrm{MW}$ and its efficiency is $32.44 \%$ in the operating conditions. The change in ambient temperature has a direct impact on the exergy performance of the gas turbine. Exergy destruction increases with air increase in temperature while the exergy efficiency decreases. The effects of air humidity, of compression ratio and fuel air ratio inside the combustion chamber on the performance of the gas turbine will be examined shortly.

\section{References}

1. W. Al Doori, Exergy analysis of a gas turbine performance with effect cycle temperatures, IJRRAS 13, 2 (2012)

2. D. P. S. Abam, and N. N. Moses, Computer Simulation of a Gas Turbine Performance, Global Journal of Researches in Engineering 11, 1 (2011)

3. E. Kakaras, Inlet Air Cooling Methods for Gas Turbine Based Power Plant, ASME, 128, (2006) 312-317

4. Yunus A. Cengel and Michael A. Boles, Thermodynamique, une approche pragmatique, Chenelière Mc Graw Hill, Montréal, Canada (2008)

5. Ibrahim Dincer \& Marc A. Rosen, Exergy, Energy, Environment and Sustainable Development, Elsevier, (2007) 2-12.

6. T. J.Kotas, The Exergy Method of Thermal Plant Analysis, University of London, U.K (1985) 38- 41

7. Manuel général volume 0 , document $\mathrm{N}^{\circ}$ : PP-AAA-PP1170 KBR-Sonatrach- Projet du Nouveau Train de GNLSkikda, Algérie. 